\title{
The War On Fraud: Reducing Cheating In The Classroom
}

David Hayes, (dhayes1@1su.edu), Louisiana State University

Kathy Hurtt, (Kathy_Hurtt@baylor.edu), Baylor University Sarah Bee, (bees@seattleu.edu), Seattle University

\begin{abstract}
The purpose of this article is to alert and inform the reader of the rampant amount of fraud (cheating) that is taking place in the classrooms across the country and to provide some measures that can be employed to reduce the likelihood of it happening in your classroom. Cheating is analyzed and diagnosed utilizing the components of the fraud triangle (pressure, opportunity, and rationalization). Activities to promote ethical behavior and making it more difficult to rationalize cheating are proposed. Strategies for reducing the opportunity to cheat are also included. "In the broadest sense, fraud can encompass any crime for gain that uses deception as its principal modus operandi" (Wells, 2005)
\end{abstract}

\section{INTRODUCTION}

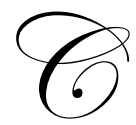

heating is reaching epidemic proportions worldwide (Desruisseaux, 1999). There is cheating in professional sports (use of steroids), cheating in business (fraudulent financial statements), cheating in elementary schools, cheating in college, and even cheating to get accepted into college (Wall Street Journal, 2005). Studies have shown that $75 \%$ to $80 \%$ of all college students cheat on at least one assignment or test (Bell, 2005). Unfortunately, accounting majors are not exempt from this trend. A recent article stated that at one Midwestern school, over half of the academic misconduct cases at the School of Business involved accounting majors (Pillsbury, 2004). Similarly, Introduction to Computing and Introduction to Programming classes have reported high incidences of cheating. At another school, over 70\% of all cheating cases originated in computing classes (Ozment et al., 2000). Accounting information systems classes have many of the same characteristics as these introductory computing courses - a new subject with students experiencing high stress in an unfamiliar environment along with the traditional grade pressures. This seems to indicate that while all accounting classes are susceptible to cheating; accounting information systems faculty might be even more likely to encounter cheating in their classrooms. This cheating behavior is critical to nip in the bud as the literature suggests that students who are academically dishonest often transfer this undesirable behavior to the corporate environment after graduation (Chapman et al., 2004, 248).

More so than in other disciplines, cheating by accountants can have serious societal and economic consequences. One only has to look at the recent accounting failures such as Enron and WorldCom to see the effects of individuals who are willing to commit fraud to get ahead. The capital markets depend on investor confidence in the integrity of the accounting profession and their representation through financial statements. Thus, both accounting educators teaching traditional accounting classes and accounting information systems educators must be aware of the potential for students to cheat and be prepared to act swiftly and with authority to prevent cheating. However, many accounting faculty are unfamiliar with today's cheating tactics and prevention opportunities.

In this paper we will discuss several types of academic fraud (including cheating) and discuss some measures that can be employed to reduce the likelihood of it happening in your classroom including activities to promote ethical behavior, strategies for reducing the opportunity to cheat and increasing the likelihood of detection. Many of these items are applicable to general classroom settings including an AIS classroom, while those addressing flowcharting and modeling problems, as well as Excel and Access controls are directed more specifically to AIS educators. The remainder of this paper is organized as follows. First, we discuss the fraud triangle and its relation to violations of 
academic integrity. Next, we discuss methods students employ to commit academic fraud and ways faculty members can reduce the opportunity to cheat. Finally, we suggest methods for staying up-to-date on developments in the cheating area.

\section{THE FRAUD TRIANGLE}

Romney \& Steinbart $(2003,277)$ define fraud as any means to gain an unfair advantage and include: lying, suppression of the truth, tricks, cunning and violation of trust. Wells $(2005,13-20)$ describes the research of Donald R. Cressey in discussing what has become known as the fraud triangle (see Figure 1).

\section{Figure 1: The Fraud Triangle}

\section{Perceived Opportunity}

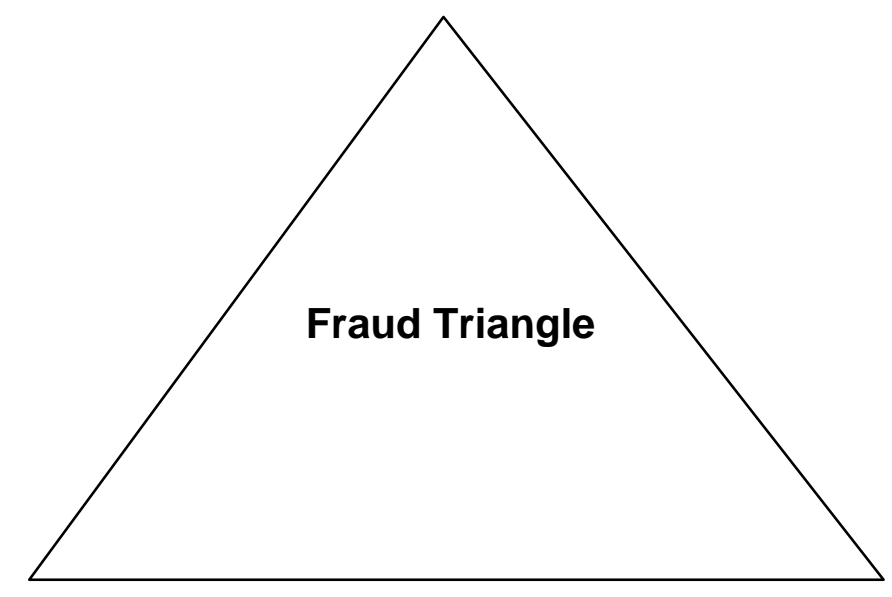

\section{Perceived Pressure}

Rationalization

The triangle suggests that for fraud to occur there must be three elements: perceived pressure, perceived opportunity and rationalization. Increases in the components of the triangle result in a higher likelihood of fraud occurring. Although the fraud triangle is used most often to discuss financial fraud, a closer look at research on why students cheat indicates that student cheating behavior falls within the elements of the fraud triangle. Gehring, Nuss and Pavela (1986) provide a list of factors shown to contribute to student cheating. We've indicated (in italics) to what element of the fraud triangle each factor relates:

- $\quad$ Students claim to be unclear about what behaviors constitute academic dishonesty (rationalization).

- $\quad$ Students believe that what they learn isn't relevant to their future career goals (rationalization).

- Student values have changed. Succeeding at any costs has become a cherished value (perceived pressure).

- Increased competition for enrollment in high demand disciplines and admission to prestigious graduate and professional schools prompt students to cheat to improve their grades, not just to avoid failure (perceived pressure).

- $\quad$ Examinations are not properly secured and faculty members are casual about proctoring exams. Assignments and examinations are repeated frequently from semester to semester (perceived opportunity).

- $\quad$ Faculty members may avoid using campus disciplinary procedures to avoid additional time requirements by simply giving those suspected of cheating a lower or failing grade (perceived opportunity). 
As this list demonstrates, the fraud triangle provides a structure for examining student cheating and developing prevention and detection techniques.

\section{Perceived Pressure}

Perceived pressure in an academic context is extensive. According to Whitley \& Keith-Spiegel (2002, 23), student pressure falls into six broad categories: 1) performance concerns (e.g. failing a course, grade pressure), 2) external pressures (e.g. academic pressures, such as work load or number of tests on one day, or nonacademic pressures, such as parental expectations, GPA required for financial aid, etc.), 3) unfair professors, 4) lack of effort (not putting in enough effort to succeed so pressure is increased), 5) other loyalties such as helping a friend or helping a member of a fraternity or sorority, 6) other items (such as viewing cheating as a game or a challenge). Typically, a student's motivation for cheating is to get a better grade and eventually to secure a job. The emphasis placed on grades by job recruiters creates an environment of intense competition which feeds the motivation (pressure) a student might have to cheat. Most faculty realize the importance placed on grades is outside their control. Because it is difficult for a faculty member to reduce the perceived pressure felt by students, it is even more important to focus on those elements that are easier to influence (rationalization and perceived opportunity).

\section{Rationalization}

Rationalization allows a student to justify cheating by creating a reason for cheating that is more compelling than honesty or integrity. Common student justifications include: cheating hurts no one; no one ever gets caught; friends come first or he/she needed my help; I only cheat in classes that aren't important to my major; everyone does it; I could lose my scholarship (or my parents will kill me) if I don't do well (Pillsbury, 2004; Whitley; Keith-Spiegel, 2002). Yet instructors are training students for a profession in which individuals often work alone and the evidence that work is performed is often only the attestation of the individual. Accountants, especially those in public practice, are held to a high standard of integrity and the public seems to believe that entry into this profession should be based on an individual's high level of personal integrity. This expectation for integrity must be integrated into the students' personal morality through repeated ethical training in all accounting classes and we believe that each faculty member should stress the importance of individual integrity and discuss how many of the rationalizations are, in fact, untrue.

Rationalization includes a belief on the part of the cheater that what they are doing is not actually unethical. This is especially true when technology is used to cheat or defraud. A student might find shoplifting software from a computer store reprehensible, but will illegally copy a software program from a friend. Most students would not break into a physical office, but see hacking into a computer system as a challenge rather than an ethical breach. Digital materials can be duplicated easily; a student might argue that it is not "stealing" if the article taken without attribution leaves the original in place and undamaged.

Some researchers suggest that the most effective way to help students develop ethical behavior is if the university has a formal training program. Kibler, Nuss, Paterson and Pavela (1988) state this program should include a clearly written policy, opportunities for discussion and dialogue, equitable arbitration procedures, the role of sanctions, and importance of instructional settings. The academic integrity policy should be included in all syllabi and discussed the first day of class. Class discussions which support the university's ethics policy are important. Frequent discussions of ethical dilemmas underscore the value (tone at the top) the university places on integrity. Teachers should articulate values and publish conduct codes. Ethical behavior should be reinforced, and non-ethical behaviors should be dealt with in a consistent manner. Technology misuse should be dealt with in the same manner as "traditional" cheating. Other activities to promote ethical behavior include: devoting a class session to an ethics speaker, discussions of the transfer of unethical behavior in college to unethical behavior in the workplace, ethics debates, discussions of the faculty member's feelings and reactions to unethical behavior by students. Case studies for class discussion can be found in Appendix A. The goal of ethics training is to ensure that a student has a set of principles to guide them rather than a set of rules. By applying guidelines rather than following rules, students engage in higher level thinking processes and learn behaviors that will likely continue into their profession (Johnson, 1998). 


\section{Perceived Opportunity}

Perceived opportunity is the third piece of the fraud triangle and lends itself to internal controls and faculty intervention more readily than the other two elements. A student perceives an opportunity to cheat when he or she identifies a method to cheat. There are literally hundreds of ways students can cheat and there are numerous references available for those individuals looking for ideas on how to cheat.

Many faculty are unaware of references such as Bob Corbett's book, The Cheater's Handbook: The Naughty Student's Bible. For students who wish to obtain "help" on written assignments, there are numerous websites such as School Sucks.com (http://www.schoolsucks.com/), Cheathouse.com (http://www.cheathouse.com/), and Essay Finder.com (http://www.essayfind.com/). It is interesting to note that topics such as accounting ethics, accounting systems and also specific case analyses can be located at these sites. For programming assignments, Rent a Coder.com (http://rentacoder.com/RentACoder/default.asp) can be used. At this site, the buyer submits a copy of what they want to have coded (i.e. the homework assignment or take-home exam) and receives bids from individuals who are willing to complete the coding. The authors are aware of one individual who received multiple bids of under $\$ 10$ to code an assignment along with the offers to insert comments to explain why the coder had done what he/she had done, and to insert deliberate errors. A request for what techniques had been covered in class was included with the offers, so that the coder would not write code that was too sophisticated for the assignment. It is obvious from this brief review that students have considerable opportunities to cheat. One of the best defenses for a faculty member is an awareness of cheating methods and the next section of this paper deals with methods students have used to cheat.

\section{Methods of Committing Academic Fraud}

It should be said that the ways to cheat are limited only by students' imaginations, and that cheating methods continually increase in sophistication. One of the biggest boons to cheating has been improved technology that is readily available for lower and lower prices. Cizek $(2003,42)$ suggests grouping cheating methodologies into three broad categories: 1) giving, taking or receiving information from other person(s), 2) using prohibited materials to complete an assignment, and 3) capitalizing on a weakness to gain an advantage. Following is an abbreviated list of current cheating methods taken from our own experiences and also from several other sources that have been grouped according to the Cizek taxonomy.

\section{Giving, Taking Or Receiving Information}

- $\quad$ Student takes a picture of a page of an exam with a cell phone and sends it to a student in a later section (Pardington, 2004).

- $\quad$ Sending a text message of an exam question on either a phone or a pager while typing on a device hidden in a sleeve, under a desk or in the front pocket of a sweatshirt. A text message to a student in the same section might be "What's the answer to number one?" (Pardington, 2004).

- $\quad$ Two students sitting one desk apart share an eraser. The students write answers on the eraser and pass it back and forth (Noah, 2001).

- $\quad$ Notes (including entire chapters of texts) can be stored in electronic organizers, hand-held computers, or even sent to oneself as a page (Lathrop and Foss, 2000, 11).

- Students arrange themselves at locations and angles during an exam so they can easily pass information (Noah, 2001).

- $\quad$ On an individual Excel assignment, several students work on one computer and then all of the students turn in the same file for credit (some students might change fonts, or column sizes). Similarly, multiple students work on an individual flowcharting assignment and then each student will print the assignment and turn in the printed flowchart for a grade.

- $\quad$ Students use a code system such as tapping or hand signals to communicate back and forth (Noah, 2001).

- "Ghost" persons, knowledgeable in the subject, take the exam by impersonating the student and the actual student never takes the exam (Noah, 2001). 


\section{Using Prohibited Materials}

- Students write pertinent information on the visors of their caps, shirt cuffs, or the palms of their hands (Noah, 2001).

- $\quad$ Students write notes on a bandage, the back of a water bottle label (the water acts as a magnifying glass), on candy or gum wrappers (and rewrap the item), on a stick of gum, or on a Kleenex (Cizek, 2003).

- $\quad$ Student requested a bid for a class programming assignment at http://rentacoder.com/RentACoder/default.asp . When the bid was received, the programmer verified what had already been covered in class and offered to build in "errors" to prevent detection.

- Student "stashes" a book in the trash of the restroom. During the exam, the student asks to be excused to use the facilities and retrieves the text to look up answers and then re-stashes the text in the trash.

- Students wear a 'walkman' portable radio with headphones which has recordings of pertinent information (Noah, 2001).

- Students store answers on hand calculators then use and /or share the calculators with other students (Noah, 2001).

- $\quad$ Students buy copies of test banks and solution manuals, often off eBay, and use these without the professor's knowledge (Jaschik, 2005).

\section{Capitalizing On A Weakness}

Students appear to take the exam but do not turn one in. Later the students accuse the instructor of losing the exams and demand to be given a re-test or amenable grades (Noah, 2001).

Both a "ghost" person and the enrolled student take the exam. The "ghost" person puts the student's name on the exam and completes it. The student takes the exam, but puts a fictitious name on it. Both exams are turned in. In the end, the instructor has no alternative but to discard the extra exam (Noah, 2001)

One student creates a diversion by asking a question of the proctor/instructor so that the proctor/instructor cannot observe the other students cheating (Noah, 2001).

There are reports of students using a battery-size device called the "KEYKatcher" to capture a professor's password and obtain tests and answers (Heyman, et al., 2005).

Students take unattended or unsecured copies of tests (new or retained graded exams) when a faculty member steps out of his/her office for a brief moment (Cizek, 2003).

The above tactics used by students are enough to keep some instructors up late at night wondering what to do to reduce the likelihood of cheating occurring in their classroom. The next section provides some suggestions to combat the cheating by reducing the students' opportunities to commit fraud (cheat).

\section{REDUCING STUDENTS' OPPORTUNITIES TO CHEAT AND INCREASING THE DETECTION OF FRAUD}

It is difficult to reduce students' perceived pressure to cheat; however, reducing perceived opportunities to cheat is somewhat easier. The following are some of the tactics that have worked in our classes:

\section{- $\quad$ Early in the semester / first day of class}

- Include the school's cheating policy in the syllabus. If the school does not have a cheating policy, write one that clarifies what you view as cheating. Consider if you will treat "givers" and "receivers" the same or differently.

$\circ \quad$ On the first day of class, review the importance of accounting ethics. We have found that having a frank discussion about the research on a student's willingness to cheat in school and their subsequent cheating behavior at work opens some students' eyes and increases their consciousness. We challenge the students to be people of integrity.

- Also on the first day of class, inform the students that other students who cheat will reduce the curve for the entire class, and your objective is to make the grading as fair as possible for all. 
O Orally, as well as in the syllabus, inform students of the consequences of cheating. We find that having students consider how they might feel if they have to explain to their parents that they were caught cheating or how they would feel appearing before an honor council is a good technique.

- As a faculty member, you might want to determine if your institution issues a "FF" on the transcript. Some schools use this double "F" on transcripts in courses where the student was failed for cheating. Ask the student how they would like to be sitting in an interview and have to explain to a potential employer why they received a "FF".

\section{- In regards to exams}

- Number the exams and account for all of them after the exam is completed. Many copy machines will print copy numbers on the exams.

- In classrooms with moveable seating, rearrange the chairs to maximize distance between student seats and have students face in directions other than simply forward.

- Consider assigning seats for the exams.

- Use alphabetical seating on the first exam to learn names (take pictures of the students on the first day of class) and make two versions of the exam by either rearranging the multiple choice questions or changing one number in a problem. Keep the first and last multiple choice question on a page the same so that it is not immediately obvious to students that the exams are different.

- $\quad$ For the following exam(s), sort and seat students by their course grade to-date. Students with lower grades should be put at the front of the class so you can watch them more closely. If a student is cheating off the person in front of or beside him/her, s/he will likely receive a worse grade. However, it is extremely important that the students do not learn that this is your seating strategy or you will be revealing their rankings in the class and compromising the students' privacy.

- Require that students leave their book bags and personal items (phones, pagers, headphones, etc.) at the front of the classroom while taking the exam.

- Insist that students remove any hats.

o Occasionally walk around the room to let them know you are monitoring them.

\section{- $\quad$ Projects}

- On Excel projects, use a hidden cell and a macro to hide the student name(s) which can then be checked later. Appendix B contains screen shots of an example on how to do this, the macro code and how to obtain a copy of the spreadsheet.

- Let the students know that you will be including skills from projects on the exams. For example, you can take pictures of Excel worksheets using a software tool such as Snagit (http://www.techsmith.com/products/snagit/default.asp) which we have found to be easier to use and much more useful than the Windows screen capture, and use those screens on exams.

$\circ \quad$ On Excel or Access projects, check the file properties (File>Properties) for elements that seem out of place such as an author other than the individual turning it in, or creation dates before the beginning of the assignment. Another possibility is to use a spreadsheet and enter the date created and date accessed information, then sort the data based on date created / accessed to look for potential duplicates.

$\circ \quad$ Give computerized exams requiring the skills learned.

$\circ \quad$ On data modeling or flowcharting projects we have found that slightly modifying the project each semester helps identify the most flagrant copying from previous semesters. Examples of modifications include changes such as the method of receiving information from the customer (faxed in rather than mailed in) or changing a few terms or document names. In addition, since almost all flowcharts are unique, identical flowcharts are usually indicative of a cheating problem. 


\section{- $\quad$ Research Papers or other writing projects}

- Include in your syllabus and in the assignment a definition of plagiarism.

- Have your students turn in both paper and electronic versions of your assignment and take advantage of resources such as fee-based Turnitin.com (http://turnitin.com/) or the free service at the University of Virginia. "Copyfind" (http://plagiarism.phys.virginia.edu/software.html). These services search your students' papers for similar existing documents.

- Use Google or another search engine to look for distinctive words or sentences in your students' papers.

Listed above are some prevention techniques that have worked well for us, but some of us have still encountered students who cheat in our classes. Staying current on cheating methods is an important aspect of continuing professional education. In addition to scanning for educational pieces that deal with this topic, we have found that the Accounting Education Using Computers and Multimedia list serve (AECM@LISTSERV.LOYOLA.EDU) is a very useful resource with faculty members sharing cheating techniques, detection techniques and articles about the problem on a regular basis. Additionally, Bob Jensen, the founder of this list serve, maintains a searchable website at http://www.trinity.edu/rjensen/ that often has current information on classroom cheating.

\section{CONCLUSIONS}

Our purpose in this article was to alert and inform the reader of the disturbing amount of fraud (cheating) that is occurring nationwide, some of the methods employed by students to commit it and various tactics a faculty member can use to fight the war on fraud in his or her classroom. We have discussed fraud in terms of the elements of the fraud triangle: perceived pressure, perceived opportunity and rationalization. One of the key elements of the fraud triangle is that it predicts that by reducing any one aspect of the triangle, fraud is reduced or eliminated. We suggest that faculty members can reduce the amount of cheating that occurs by incorporating ethics training into the classroom to help eliminate the rationalization by students that occurs before cheating. We further suggest reducing the perceived opportunity to cheat by employing both preventive and detective controls. We additionally provide resources to help readers reduce the opportunity for students to cheat by employing preventive controls. The authors also provide resources to assist educators to keep informed about cheating techniques that are being used in classrooms around the world. We all recognize that fraud (cheating) is difficult, if not impossible, to eliminate but, with the appropriate controls implemented you can reduce the likelihood of it occurring in your classroom.

The authors thank reviewers, discussants, and attendees at the 2005 AIS Educators Conference for their constructive comments.

\section{REFERENCES}

1. Bell, Debbie., Encouraging faculty to report cheating, National On-Campus Report, Vol.33, No. 5, 3/1/2005, pp. 1-2.

2. Chapman, Kenneth J., Richard Davis, Daniel Toy, and Lauren Wright, Academic integrity in the business school environment: I'll get by with a little help from my friends, Journal of Marketing Education, Vol. 26, No. 3. December, pp. 236-249, 2004.

3. Cizek, Gregory J., Cheating on Tests, How to Do It, Detect It, and Prevent It, Lawrence Erlbaum Associates, Publishers, Mahwah, NJ, 1999.

4. Desruisseaux, Paul., Cheating is reaching epidemic proportions worldwide, researchers say, The Chronicle of Higher Education, Vol. 45, Issue 34, p.A45, 4/30/99.

5. Gehring, Nuss and Pavela, Issues and Perspectives on Academic Integrity, NASPA, Inc, Columbus OH, 1986.

6. Heyman, J.D., Frank Swerlow, Michaele Ballard, Steve Barnes, Tom Duffy, Lisa Gray, Jodi Mailander, Farrell and Sharon Harvey-Rosenberg, Denise Pang, and Alicia Shepherd, Cheating in the classroom, psssst... what's the answer?, PEOPLE, pp.108-111, 1/24/05. 
7. Jaschik, Scott, A new form of cheating, Inside Higher Ed News, http://www.insidehighered.com/news/2005/03/18/cheating 3/18/2005.

8. Johnson, Doug, Developing and Ethical Compass for Worlds of Learning, MultiMedia Schools, November/December, 1998.

9. Kibler, William L, Nuss, Elizabeth M.,Paterson, Brent G., and Pavela, Gary, Academic Integrity and Student Development: Legal Issues and Policy Perspectives, College Administration Publications, USA, 1988.

10. Lathrop, Ann and Kathleen Foss, Student Cheating and Plagiarism in the Internet Era. Libraries Unlimited, Englewood, CO, 2000.

11. Noah, Harold J. and Eckstein, Max A., Fraud and Education, The Worm in the Apple, Rowman and Littlefield Publishers, Inc., Lanham, MD, 2001.

12. Ozment, Andy, Alison Smith, and Wendy Newstetter, Causes for Cheating: Unclear expectations in the classroom, American Society for Engineering Education, 2000 Annual Conference Proceedings, July, 2000.

13. Pardington, Suzanne, Students cheating with cameras, text-messaging on cell phones, Contra Costa Times (Walnut Creek, CA), 02/26/2004.

14. Pillsbury, Ceil, Reflections on Academic misconduct: an investigating officer's experiences and ethics supplements, Journal of American Academy of Business, Vol. 5, pp. 446-454, 2004.

15. Romney, M. and P. Steinbart, Accounting Information Systems Ninth edition, Prentice Hall, Upper Saddle River, NJ, 2003.

16. Wall Street Journal Online, Harvard Rejects Applicants who hacked into computer, March 8, 2005; http://online.wsj.com/article/O,,SB111029921614173536.00.html

17. Wells, Joseph T., Principles of Fraud Examination, John Wiley \& Sons, Inc., Hoboken, New Jersey, 2005.

18. Whitley, Bernard E. and Keith-Spiegel, Patricia, Academic Dishonesty, An Educator's Guide, Lawrence Erlbaum Associates, Publishers, Mahwah, NJ, 2002.

\section{APPENDIX A}

\section{Suggested Resources For Ethics Cases}

\section{The AICPA Website}

The AICPA Professor/Practitioner Case Development Program develops cases for classroom use. Following is the fair use and copyright from their website, as well as abbreviated descriptions of a few of the cases available.

These cases are intended for use in higher education for instructional purposes only, and are not for application in practice. Permission is granted to classroom instructors to photocopy any case(s) for classroom teaching purposes only. All other rights are reserved. The AICPA neither approves nor endorses this case or any solution provided herein or subsequently developed. Copyright $\odot 2003$ and 1995 by the American Institute of Certified Public Accountants, Inc., New York, New York.

\section{Growth Electronics, Inc.}

This case deals with an international company which uses various methods to fraudulently manage its earnings for several years. When the fraud is eventually discovered, the company's stock price takes a huge drop, is delisted, and the company entered bankruptcy proceedings. The company's assets were eventually sold to another firm in the industry.http://www.aicpa.org/antifraud/educators_students/Fraud_Ethics_Related_Case_ Studies/Fraud_Issues/99.htm) 


\section{Detecting Vendor Fraud In A Service Industry}

This case involves a service organization where a system integration project and related internal controls were not effectively designed or operated to prevent or detect fraud..(http://www.aicpa.org /anti fraud/educators _ students/Fraud_Ethics_Related_Case_Studies/Fraud_Issues/98.htm)

\section{Dentistar, Inc.}

This is a two part case study that presents a fraud investigation engagement based upon a pair of embezzlement schemes perpetrated for personal gain by a manager in the regional office of a national provider of prepaid dental plans. The facts of the case were drawn from an actual fraud situation where Arthur Andersen was requested by corporate management to provide business fraud risk services. The case examines various techniques used to falsify the accounting records and conceal the fraudulent transactions from corporate management.(http://www.aicpa.org/antifraud/educators_students/Fraud_Ethics_Related_Case_Studies/Fraud_ Issues/105.htm)

\section{Fraud And Collusion At Bio Clinic And Comfort Clinic}

This case focuses on the underlying schemes perpetrated by employees and business associates of Bio Clinic, for the purpose of misrepresenting the financial position of the company and its affiliates during fiscal years 1994 and 1995. http://www.aicpa.org/antifraud/educators_students/Fraud_Ethics_Related_Case_Studies/Fraud_Issues/108.htm

\section{A Star Employee's Indiscretions}

A bank CEO owes his success to a star employee, Mark, whose management produces admirable returns. Mark has inappropriate relationships with several employees - and he uses bank funds to pay for his dalliances. What should the CEO do when faced with covering up for this key player's fraud-or possibly losing hisjob?http://www.aicpa.org/antifraud/business_industry_govt/leading_corporate_governance/understand_ethic _behavior/60.htm

\section{A Young CPA Stands His Ground}

Advanced Tech, Inc., is a start-up. The venture capital owners have agreed to another round of funding and brought in a new management team. The president, vice president of sales and vice president of operations are all good friends. To reduce expenses, the operations V.P. is also the acting V.P. of finance, even though he has no accounting background. After an unsatisfactory audit, the controller is fired and Manuel Gonzales, a young CPA, becomes the interim controller. Manuel has worked there less than a year and feels out of his league. Miraculously, on the last day of a critical month, the V.P. of sales announces receipt of an order that provides the business needed to meet the expectations of the venture capital owners. Manuel has to decide how far to push his opinions regarding proper cut offs for shipments-with little support among the management team for his conservative views. http://www.aicpa.org/antifraud/business_industry_govt/leading _corporate _governance/understand _ethic _ behavior 157.htm

\section{Additional Resources}

Lawrence M. Hinman at the University of San Diego maintains a web page that is "dedicated to the thoughtful discussion of difficult moral issues." At that site are numerous cases on ethical issues. While many of them might not directly relate to an accounting course, the following are two that we thought are appropriate. http://ethics.sandiego.edu/video/welcome/welcome56.html 


\section{Cheating Using Cliff Notes, By Andy Mccarthy}

This is a very brief case that raises the issue of the ethics of using Cliff notes to prepare an English assignment. http://ethics.sandiego.edu/resources/cases/Detail.asp?ID=26

\section{MP3 On Campus By Robert F. Ladenson}

This case raises the issues of MP3 file sharing on University networks. It describes several very different approaches that universities have used to deal with this and asks the student to develop a policy to deal with this problem.

http://ethics.sandiego.edu/resources/cases/Detail.asp?ID=95

\section{APPENDIX B}

\section{Excel Spreadsheet to Detect Cheating}

Panel A - Excel screen shot showing students "sign in" sheet.

I understand that this project is to be completed by only our group and that any assistance received from other students is cheating and subject to the appropriate disciplinary action as deemed appropriate by the Office of the Dean of Students. I am aware of the group project policies / rules provided and agree to abide by them.

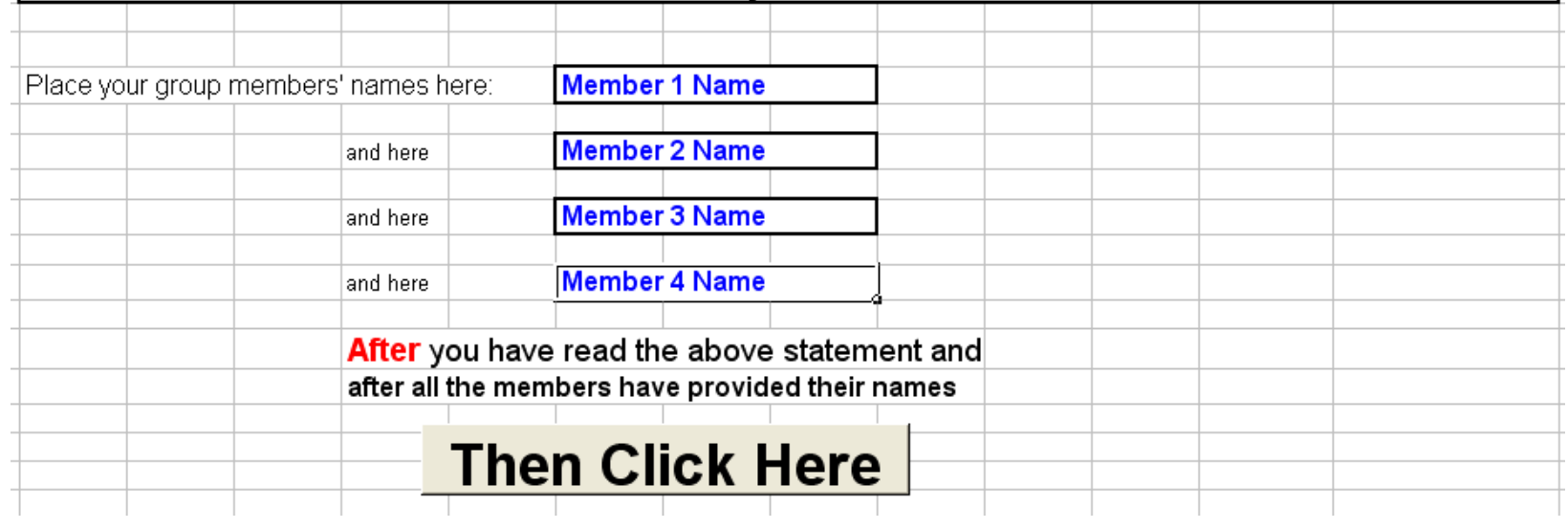

Panel B - Screen shot showing hidden names (white lettering) in Excel

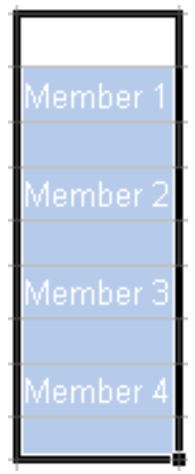

Student names are hidden on the Excel worksheets to help prevent worksheet files from being copied without detection. 


\section{Instructions For Students}

- $\quad$ Students must have macros security set to "medium" which allows macros to run. (Tools / macros / security / medium)

- $\quad$ Students must "enable macros" when they open the Excel file.

- $\quad$ Students should type their name in the blue highlighted areas (Panel A above).

Figure 2: Excel Spreadsheet To Detect Cheating (Continued)

\section{Explanation for instructors}

We create a "sign-in sheet" on the first page of the Excel workbook (Panel A above). It contains an attestation about the individuality of the work and then has a spot for the group members to enter their names in the blue highlighted area. Once the names are entered, students click on the button to enable a macro to convert their names (formulas in the column "P" rows 10 thru 16) to values. The students are unaware of this cheating control. When the students click on the second "Then click here" button, a second macro runs to save the file, and open a clean sheet where the students can do their work. If someone changes the names in column "G", it will not change them in column "P" and you can see who the original author is (see highlighted Panel B above). If you are interested in obtaining the Excel shell, it is available from the authors or you can use the following code for the two macros.

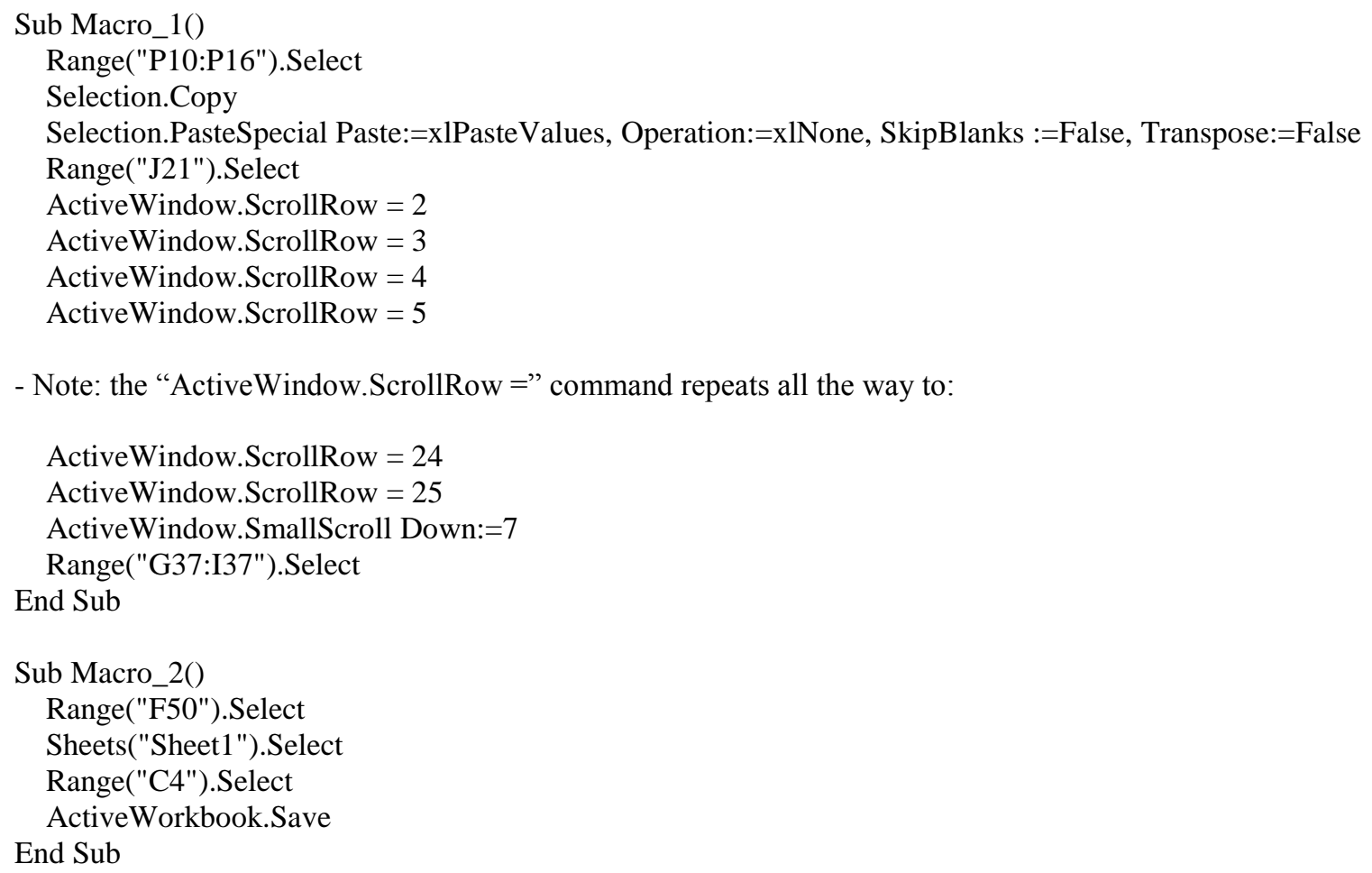

- Note: the "ActiveWindow.ScrollRow =" command repeats all the way to:

ActiveWindow.ScrollRow $=24$

ActiveWindow.ScrollRow $=25$

ActiveWindow.SmallScroll Down:=7

Range("G37:I37").Select

End Sub

Sub Macro_2()

Range("F50").Select

Sheets("Sheet1").Select

Range("C4").Select

ActiveWorkbook.Save

End Sub 


\section{NOTES}

